\title{
Key findings from a national enhanced HIV surveillance system:
}

$$
2010-2012
$$

\author{
Tarasuk $\mathbf{J}^{1 *}$, Ogunnaike-Cooke $\mathbf{S}^{1}$, Archibald $\mathrm{C}^{1}$, MacLean $\mathbf{R}^{1}$, Bennett $\mathbf{R}^{1}$, Kim $\mathbf{J}^{1}$, Malloch $\mathrm{L}^{1}$ \\ on behalf of the I-Track Principal Investigators
}

\author{
${ }^{1}$ Centre for Communicable Diseases and Infection Control, Public Health Agency of Canada, Ottawa, ON \\ ${ }^{*}$ Correspondence: jill.tarasuk@phac-aspc.gc.ca
}

\section{Abstract}

Background: People who inject drugs represent an important risk group in Canada's HIV epidemic. I-Track is a national public health surveillance system designed to monitor HIV and hepatitis $\mathrm{C}$ prevalence and associated risk behaviour factors among people who inject drugs in Canada. Information is collected through cross-sectional surveys conducted periodically at sentinel sites across Canada. I-Track Phase 3 was conducted between April 26, 2010 and August 7, 2012 across 11 participating sentinel sites.

Objective: To assess the prevalence of HIV, lifetime exposure to hepatitis $\mathrm{C}$ and associated risk behaviours among people who inject drugs in Canada to guide and help evaluate HIV and hepatitis C prevention, treatment and control activities.

Methods: People who had injected drugs in the six months prior to the interview and who met the minimum age of consent participated in an interviewer administered survey and provided a blood sample for HIV and hepatitis $\mathrm{C}$ antibody testing. Descriptive analyses were performed with sex-based comparisons.

Results: There were 2,687 people who participated in the survey. $68.2 \%$ were male, $60.9 \%$ were between the ages of 30 and 49 years and $36.2 \%$ self-identified as Aboriginal. Among the participants who provided a blood sample of sufficient quantity for testing, $11.2 \%$ were HIV seropositive and their lifetime exposure to hepatitis C infection was $68.0 \%$. Drugs commonly injected included cocaine $(64.3 \%)$, hydromorphone $(47.2 \%)$, nonprescribed morphine $(47.0 \%)$, oxycodone $(37.7 \%)$ and heroin $(26.7 \%)$. Injecting with previously used needles and/or other injection equipment was reported by $15.5 \%$ and $34.5 \%$ of participants, respectively. Just over onethird reported having two or more sex partners in the six months prior to the interview (34.4\%) and using a condom at last sex $(36.6 \%)$. The majority of participants had tested at least once in their lifetime for HIV or hepatitis C (92.9\% and $91.4 \%$, respectively). A large proportion of the participants who reported being HIV positive were under the care of a doctor $(95.0 \%)$ and nearly two-thirds were taking medications prescribed for their HIV infection at the time of the interview (66.0\%).

Conclusion: HIV seroprevalence and lifetime exposure to hepatitis C infection were high among I-Track Phase 3 participants. Although many participants reported safe injection and safe sexual practices, a high proportion of participants reported risk behaviours associated with acquisition and transmission of HIV and hepatitis C. People who inject drugs continue to represent an important risk group in Canada's HIV epidemic and the I-Track Phase 3 survey findings highlight the need for continued treatment and prevention services, as well as routine and integrated testing among people who inject drugs.

\section{Introduction}

Certain risk behaviours among people who inject drugs, such as the sharing of needles and other injecting equipment as well as unprotected sex, are associated with the transmission of blood-borne infections including HIV and hepatitis C. It is estimated that in 2011, people who inject drugs made up $13.7 \%$ of new HIV infections 
and $16.9 \%$ of those living with HIV in Canada (1). Hepatitis $\mathrm{C}$ among people who inject drugs in Canada also continues to be a major public health concern with injection drug use accounting for $61 \%$ of newly acquired hepatitis C infections in Canada each year (2).

A behavioural and biological national surveillance system, called I-Track, was developed to monitor the prevalence of HIV and hepatitis $\mathrm{C}$ as well as associated risk behaviours among people who inject drugs in Canada. The I-Track pilot was conducted from 2002 - 2003 in four sites, followed by three phases of data collection: Phase 1 from 2003 - 2005 in seven sites, Phase 2 from 2005 - 2008 in 10 sites and Phase 3 from 2010 to 2012 in 11 sites.

The ongoing monitoring of risk behaviours among persons who inject drugs serves as an early warning system for the spread of blood-borne infections in Canada. In addition, the I-Track survey results can help inform and evaluate existing public health responses to HIV and hepatitis $\mathrm{C}$ among persons who inject drugs in Canada.

This report provides selected findings from I-Track Phase 3 and is a summary of the more in-depth report (3).

\section{Methods}

I-Track is a behavioural and biological surveillance system that monitors the prevalence of HIV and hepatitis C as well as the associated risk behaviours among people who inject drugs in Canada. Information is collected through cross-sectional surveys conducted periodically at sentinel sites across Canada. I-Track Phase 3 surveys were conducted between April 26, 2010 and August 7, 2012 across 11 participating sentinel sites.

The target population was people who had injected drugs in the six months prior to recruitment and who met the minimum age of consent as per provincial requirements. Participation was voluntary, completely anonymous and based on informed verbal consent. Consenting participants were asked to complete an interviewer administered questionnaire covering demographics, drug use and injecting behaviours, sexual behaviours, HIV and hepatitis C testing and treatment history, use of health services and HIV-related knowledge. Participants were also asked to provide a biological sample which was tested for HIV and hepatitis $C$ antibodies. Testing was first performed for HIV followed by testing for hepatitis $C$ providing there was sufficient sample volume.

The data in this report are descriptive results shown for the overall sample, as well as by sex, allowing for comparisons between male and female participants for demographics; antibody laboratory results; drug use and injecting behaviours; sexual risk behaviours; HIV and hepatitis C testing, care and treatment; and use of health services. Findings for HIV-related knowledge are not presented here and can be obtained from the full report (3). Where data in the table contain small cell counts, the results should be interpreted with caution.

\section{Results}

A total of 2,687 individuals participated in I-Track Phase 3 across 11 sentinel sites in Canada: Whitehorse YK $(n=55)$, Prince George BC $(n=150)$, Edmonton AB $(n=183)$, Regina SK $(n=251)$, Thunder Bay ON $(n=138)$, Sudbury ON $(n=148)$, London ON ( $n=204)$, Toronto ON $(n=260)$, Kingston ON $(n=200)$, the SurvUDI network (sites in the province of Québec* and Ottawa, ON) $(n=937)$ and Halifax NS $(n=161)$. SurvUDI network sites in the province of Québec include Abitibi-Témiscamingue, Outaouais, Montréal, Montérégie, Québec City, SaguenayLac St-Jean, Mauricie-Central Québec and Eastern Townships. 
Table 1: Demographic characteristics of I-Track Phase 3 participants

\begin{tabular}{|c|c|c|c|c|}
\hline $\begin{array}{l}\text { Demographic characteristic and } \\
\text { incarceration history }\end{array}$ & $\begin{array}{c}\text { Total }^{1} \\
(n=2687)\end{array}$ & $\begin{array}{c}\text { Male } \\
(n=1832)\end{array}$ & $\begin{array}{l}\text { Female } \\
(n=855)\end{array}$ & p-value \\
\hline \multicolumn{5}{|l|}{ Age in years $(n=2687)$} \\
\hline Under 30 & $20.9 \%(561)$ & $16.8 \%(307)$ & $29.7 \%(254)$ & \multirow{3}{*}{$<0.001$} \\
\hline $30-49$ & $60.8 \%(1635)$ & $62.3 \%(1142)$ & $57.7 \%(493)$ & \\
\hline 50 and over & $18.3 \%(491)$ & $20.9 \%(383)$ & $12.6 \%(108)$ & \\
\hline $\begin{array}{l}\text { Self-reported Aboriginal ethnicity (First } \\
\text { Nations, Métis or Inuit) ( } n=2678 \text { ) }\end{array}$ & $36.2 \%(968)$ & $29.4 \%(537)$ & $50.6 \%(431)$ & $<0.001$ \\
\hline \multicolumn{5}{|l|}{ Sexual orientation $(n=2673)$} \\
\hline Heterosexual or straight & $88.3 \%$ (2359) & $91.9 \%(1679)$ & $80.3 \%(680)$ & \multirow[t]{2}{*}{$<0.001$} \\
\hline Gay, lesbian, bisexual, two-spirit or other & $11.7 \%(314)$ & $8.1 \%(147)$ & $19.7 \%(167)$ & \\
\hline \multicolumn{5}{|l|}{ Level of education $(n=2679)$} \\
\hline Completed some high school or less & $55.7 \%(1492)$ & $53.4 \%(974)$ & $60.6 \%(518)$ & \multirow{3}{*}{0.002} \\
\hline Completed high school & $20.9 \%(560)$ & $22.1 \%(403)$ & $18.4 \%(157)$ & \\
\hline Completed more than high school & $23.4 \%(627)$ & $24.5 \%(447)$ & $21.2 \%(180)$ & \\
\hline \multicolumn{5}{|l|}{ Monthly income $(n=2641)^{2}$} \\
\hline Less than $\$ 500$ & $14.4 \%(379)$ & $12.3 \%(222)$ & $18.7 \%(157)$ & \multirow{4}{*}{$<0.001$} \\
\hline Between $\$ 500-\$ 999$ & $39.7 \%(1049)$ & $40.3 \%(726)$ & $38.4 \%(323)$ & \\
\hline Between $\$ 1000-\$ 1999$ & $29.3 \%(775)$ & $28.8 \%(518)$ & $30.6 \%(257)$ & \\
\hline$\$ 2000$ and more & $16.6 \%(438)$ & $18.6 \%(334)$ & $12.4 \%(104)$ & \\
\hline \multicolumn{5}{|l|}{$\begin{array}{l}\text { Housing status at the time of interview } \\
(n=2669)^{3}\end{array}$} \\
\hline Stable housing & $61.3 \%(1637)$ & $57.6 \%(1049)$ & $69.3 \%(588)$ & \multirow[t]{2}{*}{$<0.001$} \\
\hline Unstable housing & $38.7 \%(1032)$ & $42.4 \%(772)$ & $30.7 \%(260)$ & \\
\hline $\begin{array}{l}\text { Proportion who had been incarcerated in the } \\
\text { six months prior to interview }(n=2683)^{4}\end{array}$ & $11.5 \%(308)$ & $12.5 \%(229)$ & $9.3 \%(79)$ & $<0.014$ \\
\hline $\begin{array}{l}\text { Proportion who had ever lived in a } \\
\text { correctional facility ( } n=2678)\end{array}$ & $82.5 \%(2210)$ & $88.5 \%(1618)$ & $69.7 \%(592)$ & $<0.001$ \\
\hline
\end{tabular}

I-Track Phase 3 participants who indicated a sex at birth other than male or female $(n=3)$ were excluded from the analyses presented in this report.

${ }^{2}$ This included all sources of income, both legal and illegal, during a one month period.

${ }^{3}$ Participants were asked to indicate where they were living at the time of the interview and responses were categorized as stable housing or unstable housing. Stable housing included: living in an apartment or house or a relative's apartment or house at the time of the interview. Unstable housing included: living in a friend's place, hotel or motel room, rooming or boarding house, shelter or hostel, transition or halfway house, drug treatment facility, correctional facility, public place (e.g., street, squats), psychiatric institution, hospital or any other responses that were considered unstable (e.g., vehicle, tent, anywhere outdoors).

${ }^{4}$ Participants were provided with a list of housing options and asked to select all the places where they had lived in the six months prior to interview. Participants who selected a correctional facility (jail, corrections, prison) are presented here.

Table 1 identifies the socio-demographic characteristics of Phase 3 participants were similar to those of previous I-Track phases; a large proportion of participants were male $(68.2 \%)$ and the largest proportion of participants were between the ages of 30 and 49 years $(60.9 \%)$, with a significantly higher proportion of male participants than female participants in this age group $(62.3 \%$ versus $57.7 \%)$ and in the 50 and over age group (20.9\% versus $12.6 \%$ ). Although a large proportion of I-Track participants self-reported their sexual orientation as heterosexual or straight (88.3\%), a significantly higher proportion of females than males self-identified as gay, lesbian, bisexual, two-spirit or other $(19.7 \%$ versus $8.1 \%)$.

Over one-third (36.2\%) of participants self-identified as Aboriginal (First Nation, Métis or Inuit), which is well above the proportion of self-identified Aboriginal persons among the general Canadian population. According to 2011 data from the National Household Survey, $4.3 \%$ of the total Canadian population self-identify as Aboriginal (4). 
There was substantial variation across sites with respect to the proportion of participants that self-reported their ethnicity as Aboriginal. For example, $89.6 \%$ of participants in Regina and $84.7 \%$ of participants in Edmonton selfidentified as Aboriginal while only $19.1 \%$ of participants in London and $13.7 \%$ of participants in the SurvUDI network self-identified as Aboriginal (data not shown). In addition, a significantly higher proportion of female participants across all sites self-identified as Aboriginal ( $50.6 \%$ of females versus $29.4 \%$ of males).

Over half (55.7\%) of participants reported having less than a high school education, with a significantly higher proportion of female participants reporting a lower level of education as compared to their male counterparts. Over one-third (39.7\%) of participants reported that their monthly income was in the range of $\$ 500$ and $\$ 999$, though there was considerable variation across participants and significant differences were noted between males and females.

Over one-third $(38.7 \%)$ of all participants reported living in unstable housing at the time of the interview, with a significantly higher proportion of males reporting unstable housing. More than one-tenth $(11.5 \%)$ reported having lived in a correctional facility in the six months prior to the interview; among males, this proportion (12.5\%) was significantly higher as compared to females $(9.3 \%)$. A large proportion of all participants $(82.5 \%)$ reported that they had, at some time in their lives, been incarcerated; the proportion of males that reported a history of incarceration was significantly higher as compared to the proportion of females (88.5\% versus $69.7 \%)$. Both unstable housing and incarceration present challenges to the prevention and control of HIV and other blood-borne infections among persons who inject drugs in Canada as both are known as high-risk injecting environments $(5,6)$.

Table 2: HIV and hepatitis C laboratory results of I-Track Phase 3 survey participants

\begin{tabular}{|c|c|c|c|c|}
\hline Laboratory results & Total & Male & Female & p-value \\
\hline \multicolumn{5}{|c|}{ HIV seroprevalence (among participants who provided a blood sample, $n=2593)^{1}$} \\
\hline HIV seropositive & $11.2 \%(291)$ & $11.6 \%(205)$ & $10.4 \%(86)$ & 0.387 \\
\hline $\begin{array}{r}\text { Proportion of HIV seropositive } \\
\text { participants who were aware of their } \\
\text { HIV positive status }(n=281)^{2}\end{array}$ & $78.6 \%(221)$ & $78.7 \%(155)$ & $78.6 \%(66)$ & 0.984 \\
\hline \multicolumn{5}{|c|}{ Lifetime exposure to hepatitis C (among participants who provided a blood sample, $n=2575)^{3}$} \\
\hline Hepatitis C seropositive & $68.0 \%(1750)$ & $67.9 \%(1192)$ & $68.1 \%(558)$ & 0.899 \\
\hline \multicolumn{5}{|c|}{$\begin{array}{l}\text { HIV and hepatitis C serostatus (among participants who provided a biological sample of sufficient } \\
\text { quantity for testing of both HIV and hepatitis C antibodies, } n=2575 \text { ) }\end{array}$} \\
\hline Seropositive for HIV only ${ }^{1}$ & $1.7 \%(43)$ & $2.0 \%(35)$ & $1.0 \%(8)$ & \multirow{4}{*}{0.312} \\
\hline Seropositive for hepatitis C only ${ }^{3}$ & $58.5 \%(1505)$ & $58.4 \%(1025)$ & $58.6 \%(480)$ & \\
\hline Seropositive for both HIV and hepatitis $\mathrm{C}^{1,3}$ & $9.5 \%(245)$ & $9.5 \%(167)$ & $9.5 \%(78)$ & \\
\hline Seronegative for both HIV and hepatitis C & $30.4 \%(782)$ & $30.1 \%(529)$ & $30.9 \%(253)$ & \\
\hline
\end{tabular}

${ }^{1}$ HIV testing of dried blood spot (DBS) specimens was performed using the AVIOQ HIV-1 EIA assay. Confirmatory testing was subsequently performed using the Bio-Rad GS HIV-1 Western Blot assay. A positive result indicated a current HIV infection.

${ }^{2}$ Participants who reported that their last HIV test result was positive and who were found to be HIV seropositive based on testing of the biological specimen provided at the time of interview were classified as being aware of their HIV positive status.

${ }^{3}$ Hepatitis C testing of DBS specimens was performed using the Ortho HCV version 3.0 EIA. Confirmatory testing was not performed for samples that tested positive. A positive result indicated past or present hepatitis $\mathrm{C}$ infection and did not discriminate acute from chronic or resolved infection.

Overall, HIV seroprevalence and lifetime exposure to hepatitis $C$ infection were high (Table 2). 11.2\% of the survey participants who provided a biological sample of sufficient quantity for testing were HIV positive and $68.0 \%$ were seropositive for hepatitis $\mathrm{C}$. No significant differences in HIV and hepatitis $\mathrm{C}$ seroprevalence were found between males and females. Although it is not possible to determine the proportion of participants that were coinfected with HIV and hepatitis $C$ at the time of interview due to the nature of the laboratory test used (i.e., it was not possible to distinguish present from past hepatitis $C$ infection), the proportion of participants who were seropositive for both HIV and hepatitis C $(9.5 \%)$ nevertheless highlights the potential for multiple infections to complicate treatment responses as well as health outcomes among people who inject drugs in Canada. 
The necessity of routine and integrated HIV and hepatitis $C$ testing among people who inject drugs cannot be overstated. It was found that only $78.6 \%$ of I-Track Phase 3 participants who tested positive for HIV based on the biological sample provided at the time of interview were aware of their infection or alternatively, that $21.4 \%$ of seropositive participants were unaware of their HIV positive status. Individuals who are unaware of their infection status are not able to benefit from treatment and counselling services and, moreover, cannot take measures to reduce their risk of HIV transmission to others. Furthermore, testing provides an opportunity to increase awareness of safe injection and sexual practices among people who inject drugs, as well as an opportunity to link individuals to available health and social support services.

Table 3: Drug use and injecting behaviours of I-Track Phase 3 survey participants

\begin{tabular}{|c|c|c|c|c|}
\hline Drug use behaviour & Total & Male & Female & p-value \\
\hline $\begin{array}{l}\text { Proportion who first injected before the } \\
\text { age of } 16 \text { years }(n=2669)\end{array}$ & $15.4 \%(412)$ & $14.0 \%(255)$ & $18.5 \%(157)$ & 0.003 \\
\hline \multicolumn{5}{|l|}{$\begin{array}{l}\text { Most commonly reported injection drugs } \\
\text { used in the six months prior to interview }\end{array}$} \\
\hline $\begin{array}{rr}\text { Cocaine } \\
\text { Col }\end{array}$ & $64.3 \%(1724)$ & $66.0 \%(1206)$ & $60.8 \%(518)$ & 0.009 \\
\hline Hydromorphone & $47.2 \%(1265)$ & $47.1 \%(861)$ & $47.4 \%(404)$ & 0.890 \\
\hline Morphine (non-prescribed) & $47.0 \%(1259)$ & $45.0 \%(822)$ & $51.3 \%(437)$ & 0.002 \\
\hline Oxycodone & $37.7 \%(1012)$ & $36.8 \%(673)$ & $39.7 \%$ (339) & 0.143 \\
\hline $\begin{array}{rr}\text { Heroin } \\
\end{array}$ & $26.7 \%(716)$ & $27.5 \%(503)$ & $25.0 \%(213)$ & 0.170 \\
\hline \multicolumn{5}{|l|}{$\begin{array}{l}\text { Most commonly reported person with } \\
\text { whom participants injected in the six } \\
\text { months prior to interview }{ }^{2}\end{array}$} \\
\hline No one (i.e., injected alone) & $59.3 \%(1588)$ & $60.2 \%(1101)$ & $57.2 \%(487)$ & 0.145 \\
\hline Friend(s) or people they knew well & $50.5 \%(1354)$ & $49.0 \%(896)$ & $53.8 \%(458)$ & 0.020 \\
\hline Regular sex partner(s) ${ }^{3}$ & $31.0 \%(831)$ & $24.8 \%(453)$ & $44.4 \%(378)$ & $<0.001$ \\
\hline People they didn't know well & $17.8 \%(478)$ & $18.1 \%(331)$ & $17.3 \%(147)$ & 0.604 \\
\hline Family member(s) & $10.6 \%(285)$ & $8.0 \%(147)$ & $16.2 \%(138)$ & $<0.001$ \\
\hline $\begin{array}{l}\text { Proportion who had used a sterile needle } \\
\text { and/or syringe at last injection }(n=2663)^{4}\end{array}$ & $94.5 \%(2516)$ & $94.7 \%(1721)$ & $94.0 \%(795)$ & 0.433 \\
\hline $\begin{array}{l}\text { Proportion who had injected with a used } \\
\text { needle and/or syringe in the six months } \\
\text { prior to the interview ( } n=2671)\end{array}$ & $15.5 \%(415)$ & $13.7 \%(249)$ & $19.6 \%(166)$ & $<0.001$ \\
\hline $\begin{array}{l}\text { Proportion who reported that their used } \\
\text { needle and/or syringe had been } \\
\text { subsequently used by someone else for } \\
\text { injection in the six months prior to } \\
\text { interview ( } n=2646 \text { ) }\end{array}$ & $15.5 \%(409)$ & $12.7 \%(229)$ & $21.4 \%(180)$ & $<0.001$ \\
\hline $\begin{array}{l}\text { Proportion who had injected with other } \\
\text { used injection equipment in the six } \\
\text { months prior to interview }(n=2672)^{5}\end{array}$ & $34.5 \%(922)$ & $31.6 \%(576)$ & $40.9 \%(346)$ & $<0.001$ \\
\hline $\begin{array}{l}\text { Proportion who reported that their other } \\
\text { used injection equipment had been } \\
\text { subsequently used by someone else in the } \\
\text { six months prior to the interview } \\
(n=2659)^{5}\end{array}$ & $33.1 \%(880)$ & $29.7 \%(540)$ & $40.3 \%(340)$ & $<0.001$ \\
\hline
\end{tabular}




\begin{tabular}{|r|c|c|c|c|}
\hline $\begin{array}{l}\text { Most commonly reported location of } \\
\text { injection in the six months prior to } \\
\text { interview }^{6}\end{array}$ & & & & \\
Own apartment / house & $61.1 \%(1642)$ & $59.0 \%(1081)$ & $65.6 \%(561)$ & $<0.001$ \\
Friend's place & $42.1 \%(1131)$ & $40.4 \%(740)$ & $45.7 \%(391)$ & 0.007 \\
Public place & $39.4 \%(1059)$ & $41.8 \%(766)$ & $34.3 \%(293)$ & $<0.001$ \\
Hotel / motel room & $15.6 \%(419)$ & $14.6 \%(267)$ & $17.8 \%(152)$ & 0.080 \\
Vehicle $^{8}$ & $15.6 \%(419)$ & $14.4 \%(263)$ & $18.3 \%(156)$ & 0.009 \\
Rooming / boarding house & $8.2 \%(220)$ & $8.9 \%(163)$ & $6.7 \%(57)$ & 0.052 \\
\hline
\end{tabular}

${ }^{1}$ Participants recorded all drugs that they had injected for non-medicinal purposes in the six months prior to interview. The most commonly reported drugs among all participants are presented. As participants could select more than one response, the total denominator is not shown.

${ }^{2}$ Participants indicated all types of persons with whom they had injected in the six months prior to interview. The most commonly reported persons are presented. As participants could select more than one response, the total denominator is not shown.

${ }^{3}$ A regular sex partner was defined as someone with whom the participant had a relationship and with whom the participant was emotionally involved.

${ }^{4}$ This measure is also used to contribute to the Global AIDS Response Progress Reporting Indicator 2.3 (7).

${ }^{5}$ Other used injection equipment included water, filters, cookers, spoons, tourniquets, ties, swabs and acidifiers.

${ }^{6}$ Participants indicated all locations where they had injected drugs in the six months prior to interview. The most commonly reported locations among all participants are presented. As participants could select more than one response, the total denominator is not shown.

${ }_{7}^{7}$ Public place included street, park, squat, subway, etc.

${ }^{8}$ Vehicle included car, van, recreational vehicle, etc.

Several differences were noted between the drug use and injecting behaviours of males and females (Table 3 ). Overall, $15.4 \%$ of all participants reported that they had injected drugs for the first time prior to the age of 16 years, with a significantly higher proportion of females than males reporting early use of injection drugs (18.5\% versus $14.0 \%$ ). Participants reported a variety of substances that they had injected in the six months prior to interview, though cocaine was the most commonly reported among all participants (64.3\%). A significantly higher proportion of male than female participants reported injecting cocaine $(66.0 \%$ versus $60.8 \%)$, while a significantly higher proportion of female than male participants reported injecting non-prescribed morphine $(51.3 \%$ versus $45.0 \%)$.

With respect to the persons with whom participants injected in the six months prior to interview, a significantly higher proportion of females reported injecting with friend(s) or people they knew well, regular sex partner(s) or family member(s). The high proportion of participants (59.3\%) who reported injecting alone is of particular concern as injecting alone is a significant risk factor for overdose and death (8).

While a large proportion (94.5\%) of both male and female participants reported using a sterile needle at their last injection, a significantly higher proportion of female participants reported a history of high-risk injecting behaviours, including use of contaminated needles, syringes and/or other injection equipment, as well as passing on used needles, syringes and/or other used injection equipment to others. These findings, coupled with data from national routine surveillance which demonstrate that a higher proportion of female adults as compared to their male counterparts acquire HIV through injection drug use, suggest that females who inject drugs are particularly vulnerable to HIV infection (9).

Participants reported a range of locations where they had injected drugs in the six months prior to interview. The most common location was their own apartment or house and this location was reported by a significantly higher proportion of female than male participants $(65.6 \%$ versus $59.0 \%)$. A significantly higher proportion of female than male participants also reported injecting drugs at a friend's place and in a vehicle. In contrast, a significantly higher proportion of male than female participants reported injecting drugs in a public place. Overall, $39.4 \%$ of all participants reported injecting in a public place which is of notable concern as public injection drug use is associated with high-risk injection practices and, in turn, increased risk of transmission of HIV and other bloodborne pathogens (10). 
Table 4: Sexual risk behaviours of I-Track Phase 3 survey participants

\begin{tabular}{|c|c|c|c|c|}
\hline BehaviourSexual behaviour & Total & Male & Female & p-value \\
\hline $\begin{array}{l}\text { Proportion who had two or more sex } \\
\text { partners in the six months prior to } \\
\text { interview }(n=2676)^{1}\end{array}$ & $34.4 \%(920)$ & $31.3 \%(572)$ & $40.9 \%(348)$ & $<0.001$ \\
\hline $\begin{array}{l}\text { Proportion who had used a condom at } \\
\text { last sex (among participants who } \\
\text { reported sex in the previous month, } \\
n=2124)^{1}\end{array}$ & $36.6 \%(777)$ & $37.2 \%(505)$ & $35.4 \%(272)$ & 0.401 \\
\hline $\begin{array}{l}\text { Proportion who had a client sex partner in } \\
\text { the six months prior to interview }(n= \\
2687)^{1}\end{array}$ & $12.8 \%(343)$ & $4.7 \%(86)$ & $30.1 \%(257)$ & $<0.001$ \\
\hline $\begin{array}{l}\text { Proportion who had used a condom at } \\
\text { last sex with a client sex partner }(n=306)\end{array}$ & $77.1 \%(236)$ & $57.4 \%(35)$ & $82.0 \%(201)$ & $<0.001$ \\
\hline $\begin{array}{l}\text { Proportion who had been previously } \\
\text { diagnosed with a sexually transmitted } \\
\text { infection }(n=1732)^{2,3}\end{array}$ & $39.3 \%(680)$ & $32.7 \%(355)$ & $50.2 \%(325)$ & $<0.001$ \\
\hline
\end{tabular}

${ }^{1}$ A client sex partner was defined as someone who has given the participant money, drugs, goods or anything else in exchange for sex.

${ }^{2}$ Defined as ever being told by a health professional (e.g., doctor or nurse) as having had chlamydia, gonorrhoea, human papillomavirus, genital herpes, oral herpes or another sexually transmitted infection.

${ }^{3}$ Data on the history of diagnosis with a sexually transmitted infection was not collected in the SurvUDI network.

Use of drugs has been shown to influence sexual behaviour by increasing risk taking (Table 4). Therefore understanding the high-risk sexual behaviours (e.g., inconsistent condom use, multiple sex partners, sex trade work) of people who inject drugs in Canada is therefore of great public health importance (11). Among I-Track Phase 3 participants who reported being sexually active, female and male participants differed in their sexual behaviours. A significantly higher proportion of female than male participants reported two or more sex partners in the six months prior to interview. Among participants who reported sex in the month prior to interview, reported condom use at last sex was similar between male and female participants, albeit quite low across all participants $(36.6 \%)$. It should be noted that condom use at last sex was measured across all sex partner types. In comparison, reported condom use at last sex with a client partner was substantially higher $(77.1 \%)$ and a significantly higher proportion of female than male participants reported this behaviour ( $82.0 \%$ versus $57.4 \%)$. A significantly higher proportion of female than male participants reported having a client sex partner in the six months prior to interview (30.1\% versus $4.7 \%)$. History of a diagnosis of a sexually transmitted infection was significantly higher among female than male participants $(50.2 \%$ versus $32.7 \%)$. 
Table 5: Testing and follow up for HIV and hepatitis C of I-Track Phase 3 survey participants

\begin{tabular}{|c|c|c|c|c|}
\hline $\begin{array}{l}\text { HIV and hepatitis C tTesting, care and } \\
\text { treatment and follow up }\end{array}$ & Total & Male & Female & p-value \\
\hline \multicolumn{5}{|l|}{ HIV } \\
\hline $\begin{array}{l}\text { Proportion who had ever tested for HIV } \\
(n=2657)\end{array}$ & $92.9 \%(2468)$ & $91.9 \%(1668)$ & $95.1 \%(800)$ & 0.002 \\
\hline $\begin{array}{l}\text { Proportion who had tested for HIV within } \\
\text { the two years prior to interview (among } \\
\text { participants who self-reported being HIV } \\
\text { negative, } n=2010 \text { ) }\end{array}$ & $85.0 \%(1709)$ & $83.6 \%(1133)$ & $88.1 \%(576)$ & 0.008 \\
\hline $\begin{array}{l}\text { Proportion who reported that they were } \\
\text { under the care of a doctor for HIV at the } \\
\text { time of interview (among participants } \\
\text { who self-reported being HIV positive, } \\
n=95)^{1}\end{array}$ & $95.0 \%(95)$ & $94.2 \%(49)$ & $95.8 \%(46)$ & $0.713^{2}$ \\
\hline $\begin{array}{l}\text { Proportion who had ever taken prescribed } \\
\text { drugs for HIV (among participants who } \\
\text { self-reported being HIV positive, } n=77 \text { ) }\end{array}$ & $77.0 \%(77)$ & $80.8 \%(42)$ & $72.9 \%(35)$ & 0.351 \\
\hline $\begin{array}{l}\text { Proportion who were taking prescribed } \\
\text { drugs for HIV at the time of interview } \\
\text { (among participants who self-reported } \\
\text { being HIV positive, } n=100 \text { ) }\end{array}$ & $66.0 \%(66)$ & $75.0 \%(39)$ & $56.3 \%(27)$ & 0.048 \\
\hline \multicolumn{5}{|l|}{ Hepatitis C } \\
\hline $\begin{array}{l}\text { Proportion who had ever tested for } \\
\text { hepatitis C ( } n=2646)\end{array}$ & $91.4 \%(2417)$ & $90.3 \%(1625)$ & $93.6 \%(792)$ & 0.004 \\
\hline $\begin{array}{l}\text { Proportion who reported that they were } \\
\text { under the care of a doctor for hepatitis C } \\
\text { at the time of interview (among } \\
\text { participants who self-reported being } \\
\text { infected with hepatitis C at the time of the } \\
\text { interview, } n=1063)^{3}\end{array}$ & $48.4 \%(514)$ & $49.3 \%(358)$ & $46.3 \%(156)$ & 0.359 \\
\hline $\begin{array}{l}\text { Proportion who had ever taken prescribed } \\
\text { drugs for hepatitis C (among participants } \\
\text { who self-reported being infected with } \\
\text { hepatitis C at the time of the interview, } \\
n=1060 \text { ) }\end{array}$ & $9.5 \%(101)$ & $10.8 \%(78)$ & $6.9 \%(23)$ & 0.045 \\
\hline $\begin{array}{l}\text { Proportion who were taking prescribed } \\
\text { drugs for hepatitis } C \text { at the time of } \\
\text { interview (among participants who self- } \\
\text { reported being infected with hepatitis } C \text { at } \\
\text { the time of the interview, } n=1063 \text { ) }\end{array}$ & $2.4 \%(25)$ & $2.6 \%(19)$ & $1.8 \%(6)$ & 0.402 \\
\hline
\end{tabular}


significant differences were found between male and female participants with respect to care and treatment for HIV, except that a significantly higher proportion of self-reported HIV positive male than self-reported HIV positive female participants reported that they were taking prescribed drugs for HIV at the time of the interview $(75.0 \%$ versus $56.3 \%$, respectively). Among participants who reported being infected with hepatitis $C$ at the time of the interview, low proportions reported being under the care of a doctor and taking prescribed drugs either at the time of the interview or in the past. No statistically significant differences were found between male and female participants in terms of care and treatment for hepatitis $\mathrm{C}$, except that a significantly higher proportion of male than female participants reported that they had, at some time in their lives, taken prescribed drugs for hepatitis C (10.8\% versus $6.9 \%$, respectively).

Table 6: Use of health services and level of difficulty accessing clean needles

\begin{tabular}{|c|c|c|c|c|}
\hline Access to Health services use and access & Total & Male & Female & p-value \\
\hline $\begin{array}{r}\text { Proportion who reported use of the } \\
\text { following healthcare services in the } 12 \\
\text { months prior to interview }\end{array}$ & & & & \\
\hline \multicolumn{5}{|l|}{ Needle exchange / harm reduction facilities } \\
\hline Hospitals $(n=1732)$ & $59.4 \%(1029)$ & $57.9 \%(628)$ & $61.9 \%(401)$ & 0.105 \\
\hline Community drop-in centres $(n=1733)$ & $54.5 \%(945)$ & $55.2 \%(599)$ & $53.4 \%(346)$ & 0.464 \\
\hline Medical clinics $(n=1730)$ & $47.1 \%(815)$ & $42.7 \%(462)$ & $54.6 \%(353)$ & $<0.001$ \\
\hline Community health centres $(n=1735)$ & $44.9 \%(779)$ & $42.7 \%(464)$ & $48.5 \%(315)$ & 0.019 \\
\hline Detox or drug treatment facilities $(n=1731)$ & $32.2 \%(557)$ & $31.9 \%(346)$ & $32.6 \%(211)$ & 0.765 \\
\hline \multicolumn{5}{|l|}{ Mental health and addictions centres } \\
\hline$(n=1729)$ & $23.7 \%(409)$ & $21.6 \%(234)$ & $27.1 \%(175)$ & 0.009 \\
\hline Culturally-based services ( $n=1729$ ) & $10.0 \%(173)$ & $9.4 \%(102)$ & $11.0 \%(71)$ & 0.284 \\
\hline Sexual health centres $(n=1727)$ & $9.6 \%(165)$ & $7.3 \%(79)$ & $13.4 \%(86)$ & $<0.001$ \\
\hline \multicolumn{5}{|l|}{$\begin{array}{l}\text { Self-reported level of difficulty accessing } \\
\text { clean needles ( } n=2663)\end{array}$} \\
\hline Very easy & $81.0 \%(2158)$ & $82.2 \%(1493)$ & $78.6 \%(665)$ & \\
\hline Somewhat easy & $15.5 \%(413)$ & $15.0 \%(272)$ & $16.7 \%(141)$ & $\cap \cap \cap 6$ \\
\hline Somewhat difficult & $3.1 \%(83)$ & $2.4 \%(44)$ & $4.6 \%(39)$ & 0.000 \\
\hline Very difficult & $0.3 \%(9)$ & $0.4 \%(8)$ & $0.1 \%(1)$ & \\
\hline
\end{tabular}

The provision of health and social support services to priority populations, including people who inject drugs, is an important component of Canada's response to HIVIAIDS and other blood-borne and sexually transmitted infections. Therefore, understanding health service use among people who inject drugs in Canada is of critical importance (12). Use of healthcare services in the 12 months prior to interview varied depending on the health service in question, and, overall needle exchange or harm reduction facilities were most commonly used among all participants (89.0\%) (Table 6). Health services use was higher among female participants with a significantly higher proportion reporting that they accessed needle exchange or harm reduction facilities, medical clinics, community health centres, mental health and addictions centres and sexual health centres. A large proportion of participants $(96.5 \%)$ reported that their level of difficulty accessing clean needles was either very easy or somewhat easy and significant differences were noted between male and female participants. 


\section{Conclusion}

Overall, HIV seroprevalence and lifetime exposure to hepatitis C infection were high among I-Track Phase 3 participants. Although many participants reported safe injection and safe sexual practices (e.g., abstaining from using or sharing contaminated equipment, condom use, etc.), a high proportion of participants reported risk behaviours associated with acquisition and transmission of HIV and other sexually transmitted and blood-borne infections. These findings suggest that people who inject drugs continue to represent an important risk group in Canada's HIV epidemic and highlight the need for continued treatment and prevention services, as well as routine and integrated testing among people who inject drugs.

This enhanced HIV surveillance system is unique in Canada. I-Track data are collected by repeated crosssectional surveys at selected sentinel sites across Canada using consistent sampling and recruitment strategies over time. While it is not possible to examine causality directly, these surveillance data offer a valuable source of information for treatment and prevention services and programs at local, provincial and national levels. I-Track uses non-random, convenience sampling methods to overcome some of the inherent difficulties in accessing this hard-to-reach population. Given this, the surveillance findings may not be representative of all people who inject drugs in Canada. With the exception of the laboratory results, this report's findings are based on self-reported data that are subject to social desirability bias and it is therefore possible that certain risk behaviours were over or underrepresented.

\section{Acknowledgements}

The successful implementation of Phase 3 of I-Track was made possible through the collaboration of communitybased organizations, provincial and local health authorities, researchers and the Public Health Agency of Canada. We acknowledge and recognize the contributions of the A-Track survey participants, the survey field staff, the survey venues, the sentinel site principal investigators (Michel Alary, Patricia Bacon, Patricia Caetano, Russell Callaghan, Holly D'Angelo-Scott, Murray Fyfe, Jennifer Gratrix, Brendan Hanley, Maurice Hennink, Pascale Leclerc, Dar Malaviarachchi, Peggy Millson, Carole Morissette, William Osei, Emma Palmantier, Élise Roy, Rita Shahin, Ron Shore, Ameeta Singh, Susan Snelling, Nathan Teegee, Maureen Twigg, Bryna Warshawsky, Gaynor Watson-Creed, John Wylie), co-investigators and collaborators. We acknowledge the support from the National HIV \& Retrovirology Laboratories (Paul Sandstrom, John Kim, Laurie Malloch, Richard Pilon) and all other members of the Public Health Agency of Canada I-Track Surveillance Team (Chris Archibald, Susanna Ogunnaike-Cooke, Jill Tarasuk, Rachel Bennett, Rachel MacLean, Stephen Cule, Qiong Li).

\section{Conflict of interest}

None

\section{Funding}

This work was supported by the Public Health Agency of Canada.

\section{References}

(1) Public Health Agency of Canada. Summary: Estimates of HIV prevalence and incidence in Canada, 2011. Ottawa: PHAC; 2012.

(2) Public Health Agency of Canada. Epidemiology of acute hepatitis C infection in Canada: Results from the enhanced hepatitis strain surveillance system (EHSSS). Ottawa: Centre for Communicable Diseases and Infection Control, PHAC; 2009.

(3) Public Health Agency of Canada. Summary of key findings from the I-Track pilot survey, 2010-2012. Ottawa: PHAC; 2014. http://www.phac-aspc.gc.ca/aids-sida/publication/index-eng.php\#surveillance 
(4) Statistics Canada. 2011 national household survey: Aboriginal peoples in Canada: First Nations People, Métis and Inuit. The Daily, Statistics Canada catalogue no. 11-001-X. 2013 May 8 [cited 2014 April]. http://www.statcan.gc.ca/daily-quotidien/130508/dq130508a-eng.pdf

(5) Corneil TA, Kuyper LM, Shoveller J, Hogg RS, Li K, Spittal PM, et al. Unstable housing associated risk behaviour and increased risk for HIV infection among injection drug users. Health Place. 2006; 12(1): 79-85.

(6) Public Health Agency of Canada. HIVIAIDS epi updates, July 2010. Ottawa: Centre for Communicable Diseases and Infection Control, PHAC; 2010.

(7) UNAIDS. Guidelines: Construction of core indicators for monitoring the 2011 Political Declaration on HIVIAIDS. Geneva: UNAIDS;2011.http://www.unaids.org/en/media/unaids/contentassets/documents/document/2011/JC2215_Global_AIDS_R esponse_Progress_Reporting_en.pdf

(8) Strike C, Leonard L, Millson M, Anstice S, Berkeley N, Medd E. Ontario needle exchange programs: best practice recommendation. Toronto: Ontario Needle Exchange Coordinating Committee; 2006.

(9) Public Health Agency of Canada. At a glance - HIV and AIDS in Canada: surveillance report to December 31st, 2012. Ottawa: Centre for Communicable Diseases and Infection Control, PHAC; 2013.

(10) McKnight I, Maas B, Wood E, Tyndall MW, Small W, Lai C, et al. Factors associated with public injecting among users of Vancouver's supervised injection facility. American Journal of Drug \& Alcohol Abuse. 2007; 33(2): 319-325.

(11) Public Health Agency of Canada. HIV transmission risk: a summary of evidence. Ottawa: Centre for Communicable Diseases and Infection Control; 2013.

(12) Public Health Agency of Canada. Strengthening federal action in the Canadian response to HIVIAIDS2012 [updated 2012 August 14; cited 2014 April].

http://www.phac-aspc.gc.ca/aids-sida/fi-if/fa-if/3-eng.php 